\title{
Effect of thinning on the diameter increment in black locust (Robinia pseudoacacia L.) stands
}

\author{
DR. REDEI, K. * \& MEILBY, H. PhD** \\ *Forest Research Institute, 42-44 Frankel L. str., Budapest, 1023-HUNGARY \\ **The Royal Veterinary and Agricultural University, Department of Economics and Natural, \\ Resources, Rolighedsvej 23, 1958 Frederiksberg C, DENMARK
}

\begin{abstract}
Black locust is one of the most important stand forming species in Hungary, covering approximately $20 \%$ of the forested land (340 thousand ha) and providing $25 \%$ of the annual timber cut of the country. Hence, during the past two decades several experiments with this species have been carried out. This paper investigates the influence of thinning on the diameter increment in an experiment including four plots. One plot was left as an unthinned control plot and three plots were thinned with various thinning intensities at age 22 . The experiment was measured at ages $22,27,32$, and 36 . Apparently the thinning intensities applied on two of the plots did not come up to the intensity required to influence the diameter growth of the remaining upper-storey trees. Therefore, for a given tree size the growth of the trees on these two plots did not differ significantly from the growth of similar trees in the unthinned plot. By contrast, significant thinning effects on the diameter increment of individual trees were observed on the most heavily thinned plot. Here the diameter increment was enhanced for trees with diameters of less than $20 \mathrm{~cm}$, whereas the largest trees of the stand exhibited reduced growth. Apparently a stand density corresponding to the heavy thinning treatment $\left(F_{w}\right.$ values of 22-23) is required to get a significant thinning response. On the other hand, to avoid thinning shocks, it may be recommendable to apply two moderate thinning treatments instead of a single heavy one.
\end{abstract}

Key words: Robinia pseudoacacia L., thinning trial, diameter increment.

\section{Introduction}

Black locust (Robinia pseudoacacia L.) was the first forest tree species to be imported from North America to Europe (to France) sometime after 1601. Its rapid spread in Europe and other parts of the world (Asia Minor - Turkey, China, Korea) may be attributed to its adaptability to a wide range of growth conditions, its favourable breeding properties, frequent and abundant seed production, excellent coppicing, fast growth and high yield, as well as its highly valuable timber.

In Hungary black locust is the most widespread tree species, occupying approximately $20 \%$ of the forested land ( 340 thousand ha) and providing $25 \%$ of the annual timber cut of the country. Currently the mean crop volume of all black locust forest areas is $125 \mathrm{~m}^{3} / \mathrm{ha}$, with a mean volume of $190 \mathrm{~m}^{3} / \mathrm{ha}$ at the age of final cutting (31 years on average). In Hungary black locust stands have been established on good as well as medium or partly poor quality sites. However, for black locust stands to produce high-quality timber, the site must provide adequate moisture 
and be characterised by a well-aerated and loose-structured soil that is rich in nutrients and humus.

Black locust stands can be established with seedlings. In Hungary the most popular spacing is $2.4 \mathrm{~m}$ by 0.7 to $1.0 \mathrm{~m}$, requiring at least 4000 seedlings/ha. Alternatively, black locust stands can be regenerated by coppicing (from root suckers). In young stands of coppice origin, a cleaning operation should be carried out to adjust spacing when the stands are 3-6 years old; the stocking should be reduced to less than 5000 stems/ha.

Black locust is a fast growing tree species and up to an age of 10-15 years canopy openings caused by tending operations are closed quickly. Later canopy closure becomes slower. Height growth peaks within the first five years, while diameter growth culminates during the first decade. The culmination of the current annual increment occurs at an age of about 20 years, whereas that of the mean annual increment occurs at about age $35-40$.

In order to investigate the influence of various thinning intensities on the volume and diameter increments, several thinning trials were established in Hungary (RÉDEI, 1986, 1992, 1995). In this paper, the evaluation of one of these trials is presented.

\section{Materials and methods}

\subsection{Description of the study area}

In the past two decades several experimental plots have been established in forest regions of Hungary for investigating the growth, yield, and tending operation techniques of black locust stands. In spring 1985 four experimental thinning plots of 0.10 ha each were established in subcompartment Pusztavacs $201 \mathrm{E}$. The experiment is located in the Danube-Tisza Interflow region, in the central part of Hungary.

According to the classification of site types used in Hungary, the main ecological characteristics of the study area are:

- Forest steppe climate zone: the humidity is less than $50 \%$ in July at $2 \mathrm{pm}$, the annual precipitation is less than $600 \mathrm{~mm}$.

- Hydrology: free draining.

- Genetic soil type: combination of humic sand soils.

- Elevation: $<100$ metres

According to the Hungarian yield table for black locust stands (RÉDEI, GAL,1985a) the site class of the investigated stand is III, the third best out of $\mathrm{VI}$.

\subsection{Assessment of stand characteristics}

At age 22, 27, 32, and 36 the tree height and the diameter at breast height (d.b.h.) were measured for all trees on the four plots. Based on these measurements the following parameters were calculated: stem number, stand basal area, diameter corresponding to mean basal area, 
stand height (Lorey's height), stem volume, and stand volume. Stem volume was estimated using the volume function (SOPP, 1974):

$v=10^{-8} d^{2} h^{1}(h /[h-1.3])^{p 0}\left(p_{1} d h+p_{2} d+p_{3} h+p_{4}\right)$

where $d$ is diameter at breast height $(\mathrm{cm}), h$ is tree height $(m), p_{0}=4.00, p_{1}=-0.6326, p_{2}=20.23$, $p_{3}=0.00$ and $p_{4}=3034$.

\subsection{Thinning intensity}

To stimulate the diameter increment a thinning was carried out at age 22 in three of the four plots. Plot 1 was left as an unthinned control plot and the other three plots were thinned from below using a range of different thinning intensities, among which the treatment applied in plot 4 can be considered a heavy treatment. The resulting stem numbers after thinning were:

plot 1: control, stem number $=770$ per ha

plot 2: stem number (after thinning) $=700$ per ha

plot 3: stem number (after thinning) $=\mathbf{5} 50$ per ha

plot 4: stem number (after thinning) $=400$ per ha

To provide a description of the thinning intensity the Wilson factor $\left(F_{W}\right)$ was used: $F_{W}=100 /\left(H_{L}\right.$ $N^{1 / 2}$ ), where $H_{L}$ is Lorey's height in metres and $N$ is stem number per ha.

\subsection{Tree classification}

Before the thinning at age 22 all trees on the four plots were classified according to the tree height classification system generally used in Hungarian silvicultural practice: $1=$ dominant tree, 2 = codominant tree, 3 = intermediate (partly dominated) tree, 4 = suppressed tree. At the same occasion, all trees were classified using the silvicultural classification system generally applied in Hungarian practice: 1 = superior tree, 2 = subdominant tree, 3 = rejected tree to be removed, $4=$ dead or dying tree.

\subsection{Statistical methods}

The objective of the analysis is to identify the apparent effects of thinning on the diameter growth of black locust. Accordingly, we investigate the variation of growth between plots and height classes for each of the periods 22-27 years, 27-32 years, and 32-36 years. Furthermore, we analyse the relationship between stem diameter and diameter increment and the effect of plot (thinning), height class, silvicultural class, and period on this relationship. This analysis enables us to distinguish the effect of plot (thinning) on diameter growth from the effect of variations in the tree size composition of the strata. Unfortunately, as the experiment does not include replications, it is not possible to distinguish the effect of thinning from the effect of plot (growth conditions). 
As our first approach, we test the hypothesis of identical mean increments in each of two specific groups of trees. These tests are carried out as ordinary t-tests using the TTEST procedure of the SAS (v. 6.12) software package. Each individual comparison of two groups of trees can be considered a simple analysis of variance based on the model:

$\square D_{i j}=\square_{i}+\square_{i j}$

where $\sqcup D_{i j}$ is the observed increment of tree $j$ in group $i \in[1,2], \square_{i}$ is the true mean diameter increment in group $\mathrm{i}$, and the $\square_{i j} s$ are normal and independent errors with mean zero and equal variances. In cases where the hypothesis of equal variances is rejected, an approximate $t$ statistic is used. The degrees of freedom associated with the approximate $t$ statistic are calculated using Satterthwaite's approximation.

The analysis of the relationship between diameter and diameter increment was carried out using general linear models. The models were developed using the GLM procedure of the SAS (v. 6.12) software package. Instead of presenting separate models for each of the three periods, it seems more informative to develop all-embracing models describing the relationship between diameter and diameter increment. As both level and slope of this relationship may depend on plot (thinning), height class, silvicultural class, and period the basic formulation of the model is:

$\square D_{\text {hijst }}=\square+a_{1 i}+b_{1 h}+c_{1 t}+d_{1 s}+\left(\square+a_{2 i}+b_{2 h}+c_{2 t}+d_{2 s}\right) D_{\text {hijst }}+\square_{\text {hijst }}$

where $D_{\text {hijst }}$ is the breast height diameter $(\mathrm{cm})$ of tree $j$ in plot $i$, height class $h$, and silvicultural class $s$ at time $t ; \square D_{\text {hijst }}$ is the annual diameter increment (cm/year) in the period immediately after time $t ; \square$ and $\square$ are model parameters common to all classes; $a_{1 i}$ and $a_{2 i}$ are class-specific parameters for plot $i ; b_{1 h}$ and $b_{2 h}$ are specific for height class $h, c_{1 t}$ and $c_{2 t}$ are specific for the period following time $t$, and $d_{1 s}$ and $d_{2 s}$ are specific for silvicultural class $s$. Finally, the $\square_{\text {hijst }}$ are assumed to be normal and independently distributed random errors with mean zero and equal variances.

The possible interactions between plot (thinning intensity), height class, silvicultural class, and period were also considered in models of the above type.

\section{Results and discussion}

\subsection{Stand diameter and diameter increment}

The most important stand parameters of the plots are included in Table 1. From this table it appears that, before thinning, the mean diameter and stem number of plot 1 were slightly lower than those of plots 2-4. Therefore, after thinning at age 22, the basal area and volume of plot 3 were almost equal to those of the unthinned plot 1 , and the basal area and volume of plot 2 were even greater. As for the most heavily thinned plot (4), more than half of the original stem number and one third of the original volume was removed. All thinning treatments were carried out from below and, therefore, the average height and diameter of thinned trees were lower than those of the remaining stand. Moreover, after thinning the diameter corresponding to mean basal area 
increased consistently from $16.7 \mathrm{~cm}$ to $20.1 \mathrm{~cm}$ with increasing thinning intensity. This should be taken into account when examining the average diameter increments on the four plots. Furthermore, it should be noted that the stand heights of plots 1, 2, and 4 were almost equal before thinning, and that of plot 3 was only slightly higher. Accordingly, we may assume that the growth potential of the four plots was similar. Finally, the mortality during the observation period (age 22-36) decreased with increasing thinning intensity.

Table 1. The most important stand parameters of the four plots (Pusztavacs $201 \mathrm{E}$ )

\begin{tabular}{|c|c|c|c|c|c|c|c|c|c|c|c|c|c|c|c|c|c|c|c|}
\hline \multirow{3}{*}{$\begin{array}{l}\text { Plot } \\
\text { Number }\end{array}$} & \multirow[t]{2}{*}{ Age } & \multicolumn{5}{|c|}{ Remaining stand } & \multicolumn{5}{|c|}{ Thinning } & \multicolumn{5}{|c|}{ Before thinning } & \multicolumn{2}{|c|}{ Mortality } & \multirow[t]{2}{*}{$\mathbf{F}_{\mathrm{w}}$} \\
\hline & & $\mathrm{N}$ & $H_{L}$ & $D_{g}$ & $G$ & V & $\mathrm{N}$ & $H_{L}$ & $D_{g}$ & G & V & $\mathrm{N}$ & $H_{L}$ & $D_{9}$ & $G$ & V & $N$ & $\mathrm{~V}$ & \\
\hline & Yr. & $\mathrm{db} / \mathrm{ha}$ & $M$ & $\mathrm{~cm}$ & $\mathrm{~m}^{2} / \mathrm{ha}$ & $\mathrm{m}^{3} / \mathrm{ha}$ & $\mathrm{db} / \mathrm{ha}$ & $\mathrm{m}$ & $\mathrm{cm}$ & $\mathrm{m}^{2} \mathrm{ha}$ & $\mathrm{m}^{3} \mathrm{ha}$ & $\mathrm{db} / \mathrm{ha}$ & $m$ & $\mathrm{~cm}$ & $\mathrm{~m}^{2} / \mathrm{ha}$ & $\mathrm{m}^{3} / \mathrm{ha}$ & $\mathrm{db} / \mathrm{ha}$ & $\mathrm{m}^{3} \mathrm{ha}$ & \\
\hline \multirow{4}{*}{$\begin{array}{l}\text { Plot } 1 . \\
\text { Control }\end{array}$} & 22 & 770 & 20.0 & 16.7 & 16.84 & 177.9 & & & & & & 770 & 20.0 & 16.7 & 16.84 & 177.9 & 60 & 4.2 & \\
\hline & 27 & 760 & 21.4 & 18.3 & 20.07 & 221.9 & & & & & & & 1.4 & & 20.07 & 221.9 & 70 & & \\
\hline & 32 & 630 & 22.8 & 20.6 & 21.08 & 244.7 & & & & & & & 22.8 & 20.6 & 21.08 & 244.7 & 200 & 21.6 & \\
\hline & 36 & 630 & 23.2 & 22.0 & 23.62 & 271.4 & & & & & & 630 & 23.2 & 22.0 & 23.62 & 271.4 & 200 & 23.1 & \\
\hline \multirow{4}{*}{ Plot 2.} & 22 & 700 & 20.4 & 18.9 & 19.61 & 211.1 & 150 & 16.0 & 11.5 & 1.57 & 14.2 & 850 & 20.1 & 11 & 18 & 225.3 & & & \\
\hline & 27 & 610 & 21.0 & 21.4 & 21.86 & 241.1 & & & & & & 610 & 21.0 & 2 & 86 & 241.1 & 90 & 14.7 & \\
\hline & 32 & 510 & 22.9 & 23.6 & 22.40 & 262.2 & & & & & & 510 & 22.9 & \begin{tabular}{|l|l|}
93.6 \\
\end{tabular} & 22.40 & 262.2 & 190 & 34.5 & 18.5 \\
\hline & 36 & 510 & 23.3 & 24.9 & 24.02 & 282.1 & & & & & & 510 & 23.3 & 24.9 & 24.02 & 282.1 & 190 & 22.4 & \\
\hline \multirow{4}{*}{ Plot 3.} & 22 & 550 & 21.7 & 19.3 & 16.10 & 180.3 & 370 & 19.1 & 14.5 & 6.15 & 64.0 & 920 & 21.2 & $\begin{array}{ll}2 & 17.5 \\
\end{array}$ & 22.25 & 244.3 & & & \\
\hline & 27 & 550 & 22.2 & 21.4 & 19.44 & 221.3 & & & & & & 550 & 22.2 & \begin{tabular}{|l|l|}
21.4 \\
\end{tabular} & \begin{tabular}{l|l}
4 & 19.44 \\
\end{tabular} & 221.3 & & & \\
\hline & 32 & 500 & 23.5 & 23.2 & 21.20 & 252.0 & & & & & & 500 & 23.5 & \begin{tabular}{|l|l|}
53.2 \\
\end{tabular} & 21.20 & 252.0 & 50 & 11.7 & 19.6 \\
\hline & 36 & 500 & 24.9 & 24.2 & 23.02 & 279.0 & & & & & & 500 & 24.9 & 24.2 & 23.02 & 279.0 & 50 & 12.3 & \\
\hline \multirow[t]{4}{*}{ Plot 4.} & 22 & 400 & 21.6 & 20.1 & 12.71 & 141.8 & 500 & 18.2 & 14.2 & 7.88 & 77.6 & 900 & 20.3 & \begin{tabular}{l|l}
3 & 17.1
\end{tabular} & 20.59 & 219.4 & & & \\
\hline & 27 & 400 & 22.4 & 22.3 & 15.71 & 179.8 & & & & & & 400 & 22.4 & 422.3 & 15.71 & 179.8 & & & \\
\hline & 32 & 380 & 23.8 & 24.2 & 17.43 & 208.8 & & & & & & 380 & 23.8 & \begin{tabular}{|l|l|}
324.2 \\
\end{tabular} & 17.43 & 208.8 & 20 & 6.0 & 23.1 \\
\hline & 36 & 380 & 24.3 & 25.3 & 19.16 & 228.8 & & & & & & 380 & 24.3 & \begin{tabular}{l|l}
3 & 25.3 \\
\end{tabular} & \begin{tabular}{l|l}
3 & 19.16 \\
\end{tabular} & 228.8 & 20 & 6.3 & \\
\hline
\end{tabular}

$F_{w}$ (Wilson factor): $=100 /\left(H_{L} N^{1 / 2}\right)$

The average periodic annual diameter increments are summarised in Table 2 for each plot and height class. From this table it appears that the average diameter increment increased consistently from plot 1 to plot 4 in all three periods. On the other hand, as for the individual height classes, this increase is not reflected clearly. For most plots and periods the average diameter increment increased consistently from height class 4 to height class 1 , as the variation between height classes within plots is considerably greater than between plots for a given height class. The general increase in average diameter increment from plot 1 to 4 is most pronounced in the first period (22-27 years) where the difference between plot 1 and 4 amounts to 0.15 $\mathrm{cm} /$ year. For comparison, the difference between plot 1 and 4 in the third period (32-36 years) only amounts to $0.05 \mathrm{~cm} /$ year.

From Table 2 it also appears that the average annual diameter increment within a given height class quite often reaches its maximum value (for a given period) in plot 4 , but maximum values occur in plot 3 with a similar frequency, and the occurrence of maximum values in plots 1 and 2 is not uncommon either. Accordingly, if it were not for the reduced proportion of lower-storey trees with increasing thinning intensity, it is not likely that the highest average increment (all trees on a plot) would generally be found in plot 4 . 
Table 2. Average periodic annual increment (cm/year) for various periods, plots, and height classes

Standard errors are given in parentheses

\begin{tabular}{|c|c|c|c|c|c|c|}
\hline \multirow{2}{*}{ Period (age) } & \multirow{2}{*}{ Plot } & \multicolumn{5}{|l|}{ Height class } \\
\hline & & 1 & 2 & 3 & 4 & All \\
\hline \multirow{4}{*}{$22-27$} & 1 & $0.488(0.03)$ & $0.388(0.01)$ & $0.231(0.02)$ & $0.141(0.02)$ & $0.300(0.02)$ \\
\hline & 2 & $0.591(0.04)$ & $0.433(0.02)$ & $0.305(0.04)$ & $0.167(0.02)$ & $0.361(0.02)$ \\
\hline & 3 & $0.543(0.06)$ & $0.429(0.03)$ & $0.300(0.04)$ & $0.128(0.03)$ & $0.394(0.03)$ \\
\hline & 4 & $0.513(0.02)$ & $0.440(0.02)$ & $0.364(0.06)$ & $0.160(-)$ & $0.446(0.02)$ \\
\hline \multirow{4}{*}{$27-32$} & 1 & $0.383(0.04)$ & $0.260(0.01)$ & $0.180(0.01)$ & $0.082(0.01)$ & $0.213(0.02)$ \\
\hline & 2 & $0.363(0.03)$ & $0.287(0.02)$ & $0.142(0.02)$ & $0.081(0.02)$ & $0.219(0.02)$ \\
\hline & 3 & $0.358(0.04)$ & $0.261(0.02)$ & $0.227(0.03)$ & $0.148(0.04)$ & $0.263(0.02)$ \\
\hline & 4 & $0.335(0.04)$ & $0.333(0.02)$ & $0.204(0.03)$ & $0.100(-)$ & $0.312(0.02)$ \\
\hline \multirow{4}{*}{$32-36$} & 1 & $0.377(0.04)$ & $0.311(0.03)$ & $0.168(0.02)$ & $0.112(0.02)$ & $0.234(0.02)$ \\
\hline & 2 & $0.296(0.05)$ & $0.297(0.02)$ & $0.165(0.03)$ & $0.160(0.03)$ & $0.240(0.02)$ \\
\hline & 3 & $0.423(0.04)$ & $0.268(0.04)$ & $0.196(0.04)$ & $0.190(0.04)$ & $0.276(0.02)$ \\
\hline & 4 & $0.292(0.04)$ & $0.302(0.02)$ & $0.225(0.07)$ & $0.075(-)$ & $0.284(0.02)$ \\
\hline
\end{tabular}

In Figure 1 the diameter distributions are shown after thinning for all plots and stand ages. For plots 1 and 2 it appears that the distribution at age 22 is slightly skewed. It also appears that the unthinned plot 1 tends to develop a bimodal diameter distribution. In fact, this would not be surprising, as bimodality is a frequently reported property of diameter distributions in unthinned stands (e.g. MOHLER et al., 1978). Development of a bimodal diameter distribution implies that the stand must consist of two well-defined storeys with distinguishable levels of diameter increment. Moreover, the mortality rate of the lower storey must be so low that it does not offset the effect of the faster growth of the upper storey on the bimodality of the diameter distribution. Inspection of the developmental paths (not shown) of trees in plot 1 yields the impression that distinct levels of growth in the two storeys can actually be observed. In addition, it turns out that a diameter of $16 \mathrm{~cm}$ at age 22 constitutes a reasonable boundary between the two storeys.

A remarkable property of the diameter distributions in Fig. 1 is that the distributions of plots 1-3 all increase their spread over time, whereas the spread of the distribution in plot 4 is almost constant. This seems to indicate that the diameter increment on this plot is not as size dependent as on the other plots, i.e. compared with plots 1-3 the growth of small trees on plot 4 is enhanced, or that of large trees is reduced, or both. 


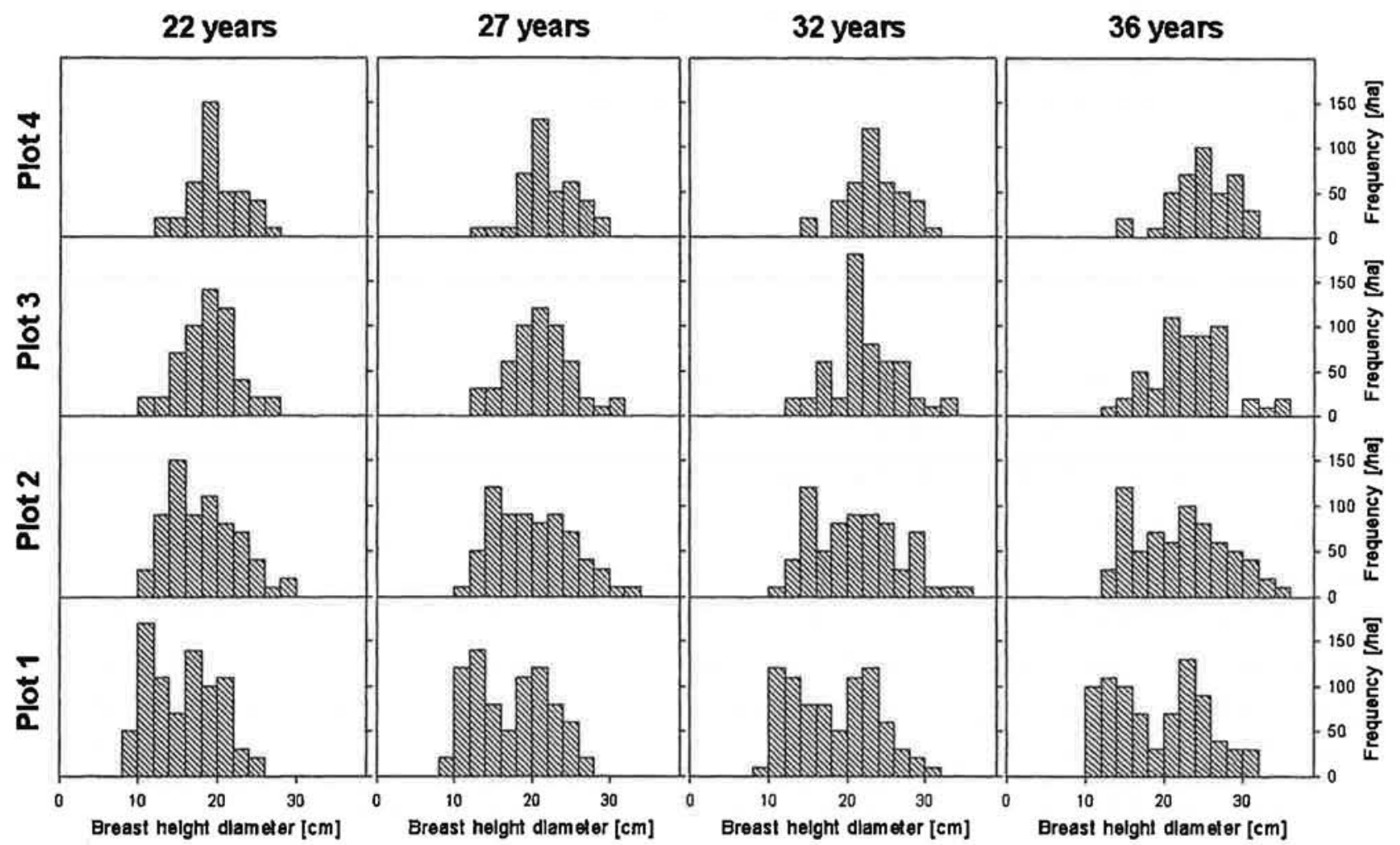

Figure 1. Diameter distributions in the four plots at ages 22, 27, 32, and 36 years.

\subsection{Testing the differences between average diameter increments}

In Table 3 the difference between the average diameter increments of the four plots have been tested for each of the three periods. Using $5 \%$ significance levels we find that in the first period (22-27 years) plot 1 differs significantly from all the other plots, whereas in the second period (27-32 years) it only differs significantly from plots 3 and 4 . The diameter increment in plot 2 differs significantly from plot 4 in the first two periods.

Table 3. Tests of equal mean diameter increment for plots within periods

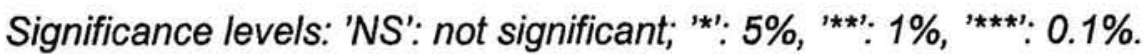

\begin{tabular}{|c|c|c|c|c|}
\hline \multirow{2}{*}{ Plot } & \multirow{2}{*}{ Period (age) } & \multicolumn{3}{|c|}{ Plot } \\
\hline & & 1 & 2 & 3 \\
\hline \multirow{3}{*}{2} & $22-27$ & * & & \\
\hline & $27-32$ & NS & & \\
\hline & $32-36$ & NS & & \\
\hline \multirow{3}{*}{3} & $22-27$ & ** & NS & \\
\hline & $27-32$ & * & NS & \\
\hline & $32-36$ & NS & NS & \\
\hline \multirow{3}{*}{4} & $22-27$ & 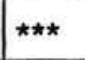 & ** & NS \\
\hline & $27-32$ & $\star \star \star \star$ & $\star \star \star \star$ & NS \\
\hline & $32-36$ & NS & NS & NS \\
\hline
\end{tabular}


No significant differences are found between any of the plots in the third period (32-36 years). As will appear below, most of the difference between plots is caused by the dissimilarities of their tree size compositions, rather than by marked differences as regards the growth of trees in a given size class.

In Table 4 the effect of increased thinning intensity on the average diameter increment has been tested for each of the height classes in each of the three periods. The table shows whether the observed effect of increased thinning intensity is positive, negative, or insignificant for a given height class. As the number of trees per height class and plot is less than 30 in all cases except one, the t-tests are generally weak. Accordingly, the significance levels applied in Table 4 are 5 , 10 , and $20 \%$. As will appear from the table the highest frequency of significant differences are found in height classes 2 and 3 . The total number of differences that are found to be significant at the $20 \%$ level is 22 and, out of these, only 4 are negative, so the effect of increased thinning intensity is positive in most cases. However, three of the significant negative effects are found in height class 1 when plots 1,2, and 3 are compared with plot 4 . Thus, it appears that the highest trees respond negatively to the strong thinning in plot 4 . By contrast, when plots 1,2 , and 3 are compared with plot 4 for height classes 2 and 3 , all significant differences are positive, indicating that increased thinning intensity generally influences the diameter increment of height classes 2 and 3 positively. On plot 4 the number of trees in height class 4 is only 1 and, therefore, in this height class no significant thinning effects are found in comparisons with plot 4 . However, in comparisons between plots 1,2, and 3 it appears that trees in height class 4 are also influenced positively by thinning.

The tests in Table 4 indicate that the relatively strong thinning on plot 4 leads to reduced diameter increment in height class 1, whereas height classes 2 and 3 respond positively. As for the moderate thinning of plot 3 the thinning effects are generally positive (or insignificant) as compared with plots 1 and 2, and the majority of the significant differences occur for height classes 3 and 4 . Finally, the effect of the light thinning applied in plot 2 only seems to last for the first period where the differences between plots 1 and 2 are significant at the $10 \%$ level for height classes 1,2 , and 3 .

Table 4. Tests of equal mean diameter increment for plots within periods and height classes

Signs indicate the effect of increased thinning intensity on average diameter increment. Significance levels: 'NS': not significant; '+' - ': $20 \%$, '++' $\%-$-': $10 \%$, '+++' $\%-$-': $5 \%$

\begin{tabular}{|c|c|c|c|c|c|c|c|}
\hline \multicolumn{2}{|c|}{} & \multicolumn{3}{c|}{ Height class 1 } & \multicolumn{3}{c|}{ Height class 2 } \\
\hline Plot & Period & Plot 1 & Plot 2 & Plot 3 & Plot 1 & Plot 2 & Plot 3 \\
\hline 2 & $22-27$ & ++ & & & ++ & & \\
& $27-32$ & NS & & & NS & & \\
& $32-36$ & NS & & & NS & & \\
\hline 3 & $22-27$ & NS & NS & & + & NS & \\
& $27-32$ & NS & NS & & NS & NS & \\
& $32-36$ & NS & ++ & & NS & NS & \\
\hline 4 & $22-27$ & NS & -- & NS & ++ & NS & NS \\
& $27-32$ & NS & NS & NS & +++ & + & +++ \\
& $32-36$ & - & NS & -- & NS & NS & NS
\end{tabular}




\begin{tabular}{|c|c|c|c|c|c|c|c|}
\hline \multicolumn{2}{|c|}{} & \multicolumn{3}{|c|}{ Height class 3 } & \multicolumn{3}{c|}{ Height class 4 } \\
\hline Plot & Period & Plot 1 & Plot 2 & Plot 3 & Plot 1 & Plot 2 & Plot 3 \\
\hline 2 & $22-27$ & ++ & & & NS & & \\
& $27-32$ & - & & & NS & & \\
& $32-36$ & NS & & & + & & \\
\hline 3 & $22-27$ & + & NS & & NS & NS & \\
& $27-32$ & + & +++ & & ++ & + & \\
& $32-36$ & NS & NS & & + & NS & \\
\hline 4 & $22-27$ & +++ & NS & NS & NS & NS & NS \\
& $27-32$ & NS & + & NS & NS & NS & NS \\
& $32-36$ & NS & NS & NS & NS & NS & NS \\
\hline
\end{tabular}

In Table 5 the differences in average annual diameter increments have been tested between periods for each of the four plots. Accordingly, this table yields an impression of the combined effect of stand age, climate, and the gradually decreasing effect of the thinning treatment for various thinning intensities. It emerges that, for all four plots, the mean annual increments differed significantly between period 1 (22-27 years) and the two other periods, whereas no significant differences are found between periods 2 and 3. Clearly, as similar results are obtained for the thinned plots 2-4 and for the unthinned plot 1, most of the difference observed between period 1 and the two other periods must be ascribed to age and climate, rather than to effects of thinning.

Table 5. Tests of equal mean diameter increment for periods within plots

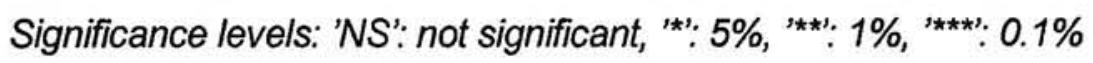

\begin{tabular}{|l|l|l|l|}
\hline \multicolumn{2}{|c|}{} & \multicolumn{2}{l|}{ Period (stand age) } \\
\hline Period & Plot & $22-27$ & $27-32$ \\
\hline \multirow{5}{*}{$27-32$} & 1 & $\star \star \star$ & \\
\cline { 2 - 4 } & 2 & $\star \star \star$ & \\
\cline { 2 - 4 } & 3 & $\star \star \star$ & \\
\cline { 2 - 4 } & 4 & $\star \star \star$ & NS \\
\hline \multirow{5}{*}{$32-36$} & 1 & $\star$ & NS \\
\cline { 2 - 4 } & 2 & $\star \star \star$ & NS \\
\hline & 3 & $\star \star$ & NS \\
\hline
\end{tabular}

\subsection{The relationship between diameter and diameter increment}

A wide range of models were tested, some of them including interactions between the class variables: plot, height class, silvicultural class, and period. It turned out that the lowest possible root mean squared error (RMSE) was $0.117 \mathrm{~cm}$, which was reached by a model that included interactions between plot and silvicultural class and between height class and silvicultural class. However, in this model there was no significant effect of plot, and the total number of non-zero parameters was 26. By comparison, models without interactions between class variables 
obtained RMSE values that were only slightly higher $(0.119-0.120 \mathrm{~cm})$ with only $13-16$ non-zero parameters. Accordingly, the final models do not include interactions between class variables.

In the final model the effect of silvicultural class is statistically significant. However, the influence of silvicultural class on the annual diameter growth is small (much less than that of height class) and, as the height and silvicultural classifications are closely related it has been decided to present two models, one with and one without silvicultural class. Apart from this, the models both include the effect of current diameter, separate levels of increment for each plot (thinning), separate levels for each height class, separate slopes for each plot, and separate slopes for each period. The two models are summarised in Tables 6 and 7. It should be noted that the RMSE and $R^{2}$ of the two models are almost equal; so - from a practical point of view - we may choose quite freely among them. For both models we tested whether the residuals could actually be assumed to originate from a normal distribution (using the Shapiro-Wilk test statistic). In both cases the test statistics were outside the significance region and we may therefore confidently assume that the residuals are actually normal.

As for the model in Table 6 the $a_{1 i} s$ are negative and the $a_{2 i} s$ are positive for plots $1-3$, and it appears that the relationship between diameter and diameter increment moves to a higher level and becomes more flat with increasing thinning intensity. The height class turns out mainly to influence the level of the relationship and it appears that the level becomes approximately 0.17 $\mathrm{cm} /$ year higher for height class 1 than for height class 4 . The isolated effect of silvicultural class is smaller and accounts for a maximum of $0.08 \mathrm{~cm} /$ year. It should be noted that for silvicultural class 2 the growth apparently does not differ significantly from class 4 , as its $d_{1 s}$-parameter is not significantly different from zero. Finally, the period mainly influences the slope of the relationship and, as was also observed in Table 5, a significant difference is observed between period 1 and the two other periods, whereas these two periods do not differ significantly from each other.

Table 6. Linear model with class-specific levels and slopes, including silvicultural class

Model: $\square D_{\text {hijst }}=\square+a_{1 i}+b_{1 h}+d_{1 s}+\left(\square+a_{2 j}+c_{2 t}\right) D_{\text {hijt }}+\square_{\text {hijst }} \quad R M S E=0.1188 \mathrm{~cm} \quad R^{2}=0.505$

\begin{tabular}{|c|c|c|c|c|c|c|c|c|l|l}
\hline \multicolumn{10}{|c}{ Parameter estimates } \\
\hline$\alpha$ & $\beta$ & Plot & $a_{11}$ & $a_{2 i}$ & Height class & $b_{1 \mathrm{~h}}$ & Silv. Class & $\mathrm{d}_{1 \mathrm{~s}}$ & Period & $\mathrm{c}_{2 \mathrm{t}}$ \\
\hline 0.2743 & -0.0065 & $\mathbf{1}$ & -0.2789 & 0.0127 & $\mathbf{1}$ & 0.1651 & $\mathbf{1}$ & 0.0795 & $\mathbf{2 2 - 2 7}$ & 0.0067 \\
\hline & & $\mathbf{2}$ & -0.2321 & 0.0103 & $\mathbf{2}$ & 0.1334 & $\mathbf{2}$ & $0.0313^{\mathrm{NS}}$ & $\mathbf{2 7}-\mathbf{3 2}$ & $-0.0003^{\mathrm{NS}}$ \\
\hline & & $\mathbf{3}$ & -0.2282 & 0.0102 & $\mathbf{3}$ & $0.0360^{\mathrm{NS}}$ & $\mathbf{3}$ & 0.0500 & $\mathbf{3 2 - 3 6}$ & 0 \\
\hline & & $\mathbf{4}$ & 0 & 0 & $\mathbf{4}$ & 0 & $\mathbf{4}$ & 0 & & \\
\hline
\end{tabular}

All class-specific parameters are calculated under the condition that the parameter of the highest numbered class is restricted to zero. Symbols: see text. NS-marked parameter estimates are not significantly different from zero (at the $5 \%$ level). Units of measurement: $D_{\text {hijst }} \mathrm{cm}, \square D_{\text {hijt: }}$ : $\mathrm{cm} /$ year.

In Table 7 the model not including silvicultural class is presented. The table shows that the effects of plot $\left(a_{1 i}\right.$ and $\left.a_{2 i}\right)$ and period $\left(c_{2 t}\right)$ are almost unchanged as compared with the model in Table 6, whereas the effect of height class has increased as a consequence of the removal of 
silvicultural class from the model. This is due to the mentioned positive relationship between height class and silvicultural class.

Table 7. Linear model with class-specific levels and slopes, not including silvicultural class Model: $\square D_{\text {hijt }}=\square+a_{1 i}+b_{1 h}+\left(\square+a_{2 i}+c_{2 t}\right) D_{\text {hijt }}+\square_{\text {hijt }} \quad R M S E=0.1197 \mathrm{~cm} \quad R^{2}=0.495$

\begin{tabular}{|l|l|l|l|l|l|l|l|l|}
\hline \multicolumn{2}{|l|}{ Parameter estimates } \\
\hline$\alpha$ & $\beta$ & Plot & $\mathrm{a}_{1 \mathrm{i}}$ & $\mathrm{a}_{2 \mathrm{i}}$ & Height class & $\mathrm{b}_{1 \mathrm{~h}}$ & Period & $\mathrm{c}_{2 \mathrm{t}}$ \\
\hline 0.2609 & $-0.0054^{\text {NS }}$ & $\mathbf{1}$ & -0.2374 & 0.0106 & $\mathbf{1}$ & 0.2242 & $\mathbf{2 2 - 2 7}$ & 0.0067 \\
\hline & & $\mathbf{2}$ & -0.1956 & 0.0084 & $\mathbf{2}$ & 0.1587 & $\mathbf{2 7 - 3 2}$ & $-0.0003^{\text {NS }}$ \\
\hline & & $\mathbf{3}$ & -0.2091 & 0.0095 & $\mathbf{3}$ & 0.0669 & $\mathbf{3 2 - 3 6}$ & 0 \\
\hline & & $\mathbf{4}$ & 0 & 0 & $\mathbf{4}$ & 0 & & \\
\hline
\end{tabular}

Explanation: see Table 6.

In Figure 2 the predicted values of annual diameter increment in the first period (22-27 years) are presented for various combinations of diameter and height class. As will appear from the figure, the overall difference between the diameter increments of various height classes is considerable. Furthermore, for height class 2 in plots 1-3 the predicted annual increment in this period varies from $0.3 \mathrm{~cm}$ to $0.55 \mathrm{~cm}$ over the $10-30 \mathrm{~cm}$ diameter range. However, for plot 4 the variation is less than $0.05 \mathrm{~cm}$ and, compared with the other three plots, trees with a diameter of less than approximately $20 \mathrm{~cm}$ exhibit increased diameter increment whereas thicker trees respond to the increased thinning intensity by decreasing diameter growth.

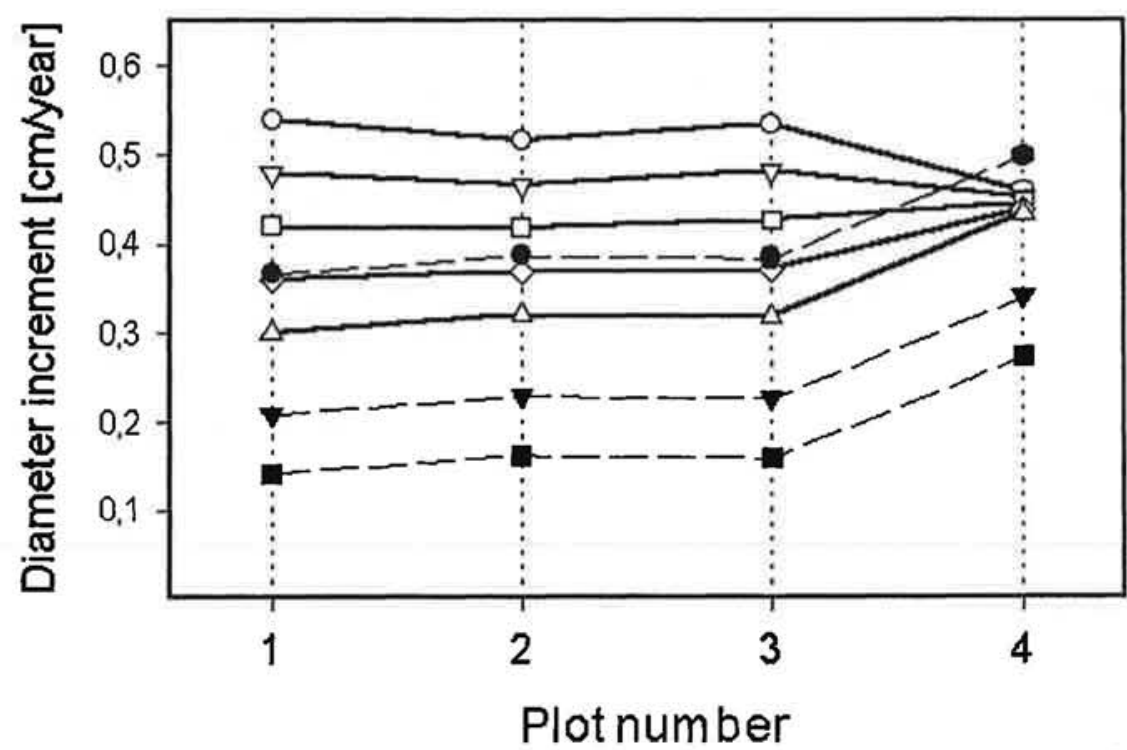

\section{2-27 years}

-O- $\mathrm{D}=30 \mathrm{~cm}, \mathrm{H}$.class 2

$\neg-\mathrm{D}=25 \mathrm{~cm}$. H.class 2

$\rightarrow \square-D=20 \mathrm{~cm}$, H.class 2

$\prec D=15 \mathrm{~cm}$, H.class 2

$\triangle \mathrm{D}=10 \mathrm{~cm}$. H.class 2

$\rightarrow \mathrm{D}=10 \mathrm{~cm}$. H.class 1

$\rightarrow-D=10 \mathrm{~cm}, \mathrm{H}$.class 3

$\rightarrow \mathrm{D}=10 \mathrm{~cm} \cdot$ H.class 4

Figure 2. Predicted annual increment in the first period (22-27 years) as depending on plot (thinning), diameter, and height class.

All predictions are calculated using the model in Table 7. D is diameter; H.class is height class. 
In the following two periods (27-32 and 32-36 years; not shown) the considerable difference between the growth of small and large diameter trees has almost disappeared on plots 1-3, and on plot 4 the relationship between diameter and diameter increment has been reversed, meaning that the predicted increment of small diameter trees exceeds that of large diameter trees. However, small diameter trees (d.b.h. $<20 \mathrm{~cm}$ ) on plot 4 still exhibit faster growth than on plots $1-3$, so the thinning response persists. On the other hand, the reduced growth of large diameter trees seems to indicate that the dominant trees experienced a thinning shock, whereas the smaller trees benefited from the thinning. Clearly, this is in agreement with the results in Table 4.

The predicted increments of trees on plots 1,2, and 3 are almost similar and, provided that the growth conditions on these plots are also similar, this implies that within the range of thinning intensities applied on plots 2 and 3 almost no thinning response occurs. Thus, as for these plots the differences observed in Table 4 are mainly caused by the varying diameter composition of each height class on the three plots. In fact, it turns out that the average diameter of trees in a given height class on plot 1 is generally $1-3 \mathrm{~cm}$ smaller at age 22 as compared with trees in the same height class on plots 2 and 3 . Similarly, the thinning effects observed in Table 3 are mainly caused by the varying tree size composition on the four plots.

\section{Conclusion}

In this experiment the stands were thinned from below. This implies that most of the thinned trees are in the lower part of the canopy (height classes 3 and 4) and, therefore, effects of thinning on the diameter increment of the remaining upper-storey trees cannot be observed at low thinning intensities. Apparently, the thinning intensities applied on plots 2 and 3 did not quite come up to the intensity required to influence the diameter growth of the remaining trees. Thus, on these plots the differences in diameter increment reported in Tables 3 and 4 are basically consequences of unequal tree size compositions. By contrast, significant thinning effects on diameter increment are observed on plot 4 . In this case, the diameter increment is enhanced for trees with diameters of less than $20 \mathrm{~cm}$, whereas larger trees exhibit reduced growth.

Many thinning experiments, some of them established in black locust stands have consistently reported increasing diameter growth with decreasing stand density (CLUTTER et al., 1983; RÉDEI 1995b). In black locust stands the experimental thinnings did not increase the periodic total wood production, but they increased the value of stands within the examined period (RÉDEI 1992,1995b). Stands thinned in time develop larger average diameters than comparable unthinned stands. This is also observed in the current experiment. From a tending operations point of view one of the most important tasks is to create suitable growing space for superior trees that exhibit the greatest diameter growth and volume increment. However, in the present experiment, it appears that the thinning intensity required to obtain a significant thinning response among medium-sized trees also implied that the largest trees of the stand experienced a thinning shock. Nevertheless, we conclude that when increment thinnings are carried out, an $F_{w}$ value of 22-23 may be preferable. This corresponds to the stand density obtained in plot 4. 
However, to prevent thinning shocks on certain sites it may be considered to carry out two moderate thinning treatments instead of a single heavy one.

\section{Acknowledgements}

The research on black locust improvement and management in Hungary has been partly supported by the Hungarian National Scientific Research Fund (OTKA-T029021).

\section{Literature}

Clutter, J.L., Fortson, J.C., Pienaar, L.V., Bristar, G.H. \& Bailey, R.L. (1983). Timber management: A quantitative approach. John Wiley and Sons, p. 66-81.

Mohler, C.L., Marks, P.L. \& Sprugel, D.G. (1978). Stand structure and allometry of trees during self-thinning of pure stands. Journal of Ecology, Vol. 66:599-614.

Rédei, K. (1986). Waldpflege in den ungarischen Robinienwäldern. Die Holzzueht. 40. 1/2. 1-4.

Rédei, K. (1992). Növedékvizsgálatok akácállományokban. [Increment investigations in black locust stands.] Erdészeti Lapok, CXXVII.3:72-73. (In Hungarian).

Rédei, K. \& Gál, J. (1985a). Akácosok fatermése. [Yield of black locust stands.] Erdészeti Kutatások, Vol. 77:195-203. (In Hungarian).

Rédei, K. (1995b). A növedékfokozó gyéritések hatása az akácosok hozamára és értékére. [The effect of increment thinning on the yield and timber value of black locust.] Erdészeti Kutatások, Vol. 85:79-90. (In Hungarian).

Sopp, L. (1974). Fatömegtáblák. [Volume tables.] Mezőgazdasági Kiadó, Budapest. (In Hungarian). 